ORIGINAL ARTICLE

\title{
Emergency department management of mild traumatic brain injury in the USA
}

\author{
J J Bazarian, J McClung, Y T Cheng, W Flesher, S M Schneider
}

Emerg Med J 2005;22:473-477. doi: 10.1136/emj.2004.019273

See end of article for authors' affiliations

Correspondence to:

Correspondence
Dr J J Bazarian,

Department of Émergency

Medicine, University of

Rochester Medical Center,

Box 655, 601 Elmwood

Ave, Rochester, NY 14642

USA; jeff_bazarian@urmc.

rochester.edu

Accepted for publication

7 November 2004
Objective: To describe the emergency department (ED) management of isolated mild traumatic brain injury (TBI) in the USA and to examine variation in care across age and insurance types.

Methods: A secondary analysis of ED visits for isolated mild TBI in the National Hospital Ambulatory Medical Care Survey 1998-2000 was performed. Mild TBI was defined by International Classification of Diseases, 9th Revision, Clinical Modification (ICD-9) codes for skull fracture, concussion, intracranial injury (unspecified), and head injury (unspecified). Available ED care variables were analysed by patient age and insurance categories using multivariate logistic regression.

Results: The incidence of isolated mild TBI cases attending ED was 153296 per year, or 56.4/100000 people. Of the patients with isolated mild TBI, $44.3 \%$ underwent computed tomography, $23.9 \%$ underwent other non-extremity, non-chest $x$ rays, $17.1 \%$ received wound care and $14.1 \%$ received intravenous fluids. However, only $43.8 \%$ had an assessment of pain. Of those with documented pain, only $45.5 \%$ received analgesics in the ED. Nearly $38 \%$ were discharged without recommendations for specific follow up. Several aspects of ED care varied by age but not by insurance type.

Conclusion: Substantial ED resources are devoted to the care of isolated mild TBI. The present study identified deficiencies in and variation around several important aspects of ED care. The development of guidelines specific for mild TBI could reduce variation and improve emergency care for this injury.
A pproximately $70-90 \%$ of traumatic brain injuries (TBIs) that occur worldwide are considered mild, defined as loss of consciousness $<30$ minutes, amnesia $<24$ hours, or peri-injury confusion/disorientation in a patient with a Glasgow Coma Scale score of $13-15 \cdot .^{1-4}$ In 1997, the World Health Organization recommended research efforts to reduce the consequences of mild TBI. ${ }^{4}$ In the USA, the National Institutes of Health has declared that mild TBI is a major public health problem and that efforts to reduce disability after a mild TBI should be a national research priority. ${ }^{5}$ Despite the term "mild", $5 \%$ of patients with this injury have traumatic abnormalities on initial head computed tomography (CT) scan and $1 \%$ require acute neurosurgical intervention. ${ }^{6}$ Post-mild TBI disability stems from cognitive, physical, psychological, and social dysfunction and results in significant disability and unemployment. ${ }^{5-10}$ Post-concussion symptoms affect up to $50 \%$ of patients with mild TBI at one month and $15-25 \%$ at one year. ${ }^{11-15}$

The emergency department (ED) is an important and overlooked component of mild TBI care. Although the ED is the point of medical contact for most patients with mild TBI, ED management of this injury has not been described. ${ }^{16}$ Because of low rates of follow up of these patients, the ED visit may be their only contact with the medical system. ${ }^{17}$ Although there are currently no mild TBI specific therapies, the diagnostics and treatments received in the ED have the potential to affect outcome. For example, in the subset of patients with mild TBI requiring neurosurgical intervention $(0.2-3 \%),{ }^{14-17}$ the mortality of those who undergo surgery within four hours of injury was found to be one third of that of patients who wait longer, underscoring the impact of rapid ED evaluation and $C T .^{18}$ Moreover, referral of patients with mild TBI directly to the neuropsychological specialists after they are discharged from the ED has been shown to reduce long term cognitive disability. ${ }^{19}{ }^{20}$ Finally, medications given soon after injury, such as serotonin reuptake inhibitors and benzodiazepines, have been shown to reduce post-concussion symptoms after mild TBI. ${ }^{21}$ Thus, the description of ED care for mild TBI, and the identification of deficiencies and variation in care, would be important first steps toward improving emergency care for this injury.

A significant variation in some aspects of ED care for mild TBI has already been reported. Several European and Canadian centres have found variations in the use of CT after mild TBI. ${ }^{15}{ }^{20-25}$ In Sweden and Norway, variation has also been reported in hospital admission rates for mild TBI, ranging from $15 \%$ to $94 \% .{ }^{18-21}$ However, these studies did not address other important aspects of ED care such as procedures, and treatments and disposition, where variation may also exist. Guidelines have been suggested as a way to reduce variation and improve care, ${ }^{26}$ and in Europe, such guidelines for mild TBI are already being developed. ${ }^{27-29}$ In the USA, the guidelines for mild TBI proposed by the American College of Emergency Physicians cover only neuroimaging and not other aspects of ED care. ${ }^{6}$ Because ED care for mild TBI in the USA has not been reported, it is unclear if further development of guidelines there is warranted.

The objective of the current study is to describe the ED management of isolated mild TBI in the USA and to analyse variation in care across age and insurance types. We sought to identify deficiencies in or variation around ED care for isolated mild TBI to determine the need for mild TBI specific guidelines. Ethical approval was not required because the study was granted exemption by the University Research Subjects Review Board under "Secondary Use of Pre-existing Data".

\section{METHODS}

We analysed the ED visit data in the National Hospital Ambulatory Medical Care Survey (NHAMCS) for the years

Abbreviations: $\mathrm{CT}$, computed tomography; $\mathrm{ED}$, emergency department; MRI, magnetic resonance imaging; NHAMCS, National Hospital Ambulatory Medical Care Survey; TBI, traumatic brain injury 
1998-2000. The NHAMCS is a multistage probability sample of approximately 25000 ED visits in the USA collected each year by the Centers for Disease Control and Prevention and the National Center for Health Statistics. The NHAMCS dataset is available to the public on the National Center for Health Statistics website. ${ }^{30}$

The Centers for Disease Control and Prevention randomly selects hospitals and clinics within geographically defined areas (primary sampling units), after adjustment for size, in order to represent the US population. ${ }^{130}$ Within each selected hospital or clinic, 50-100 ED records are randomly selected, abstracted, and entered into a database. Although data are available on visits to both outpatient clinics and EDs, we confined our analysis to ED visits. In the current study, data on only those patients meeting the International Classification of Diseases, 9th Revision, Clinical Modification (ICD-9) definition of isolated mild TBI during the years 1998-2000 were analysed.

The NHAMCS dataset does not contain information on amnesia or loss of consciousness, which are part of the clinical definition of mild TBI. Cases of mild TBI were identified using ICD-9 codes for skull fracture (800.0, 800.5, $801.0,801.5,803.0,803.5,804.0,804.5)$, concussion (850.0, 850.1, 850.5, 850.9), intracranial injury, unspecified, (854.0), and head injury, unspecified (959.01). These codes were recommended for mild TBI surveillance and research by the Centers for Disease Control and Prevention Mild Traumatic Brain Injury Work Group in October 2002. ${ }^{17}$ A patient with isolated mild TBI was defined as having only mild TBI ICD-9 codes in the diagnosis fields of the NHAMCS dataset. The exclusion of any non-mild TBI injuries or illnesses maximised

Box 1: National Hospital Ambulatory Medical Care Survey variables relevant to the ED care of mild traumatic brain injury

- Pain assessment

- Receipt of analgesics

- Mental status exam

- Receipt of analgesics for documented pain

- CT scan

- Admission to hospital

- Magnetic resonance imaging (MRI) scan

- Admission to intensive care unit

- Other $x$ ray (not chest or extremity)

- Transfer to another facility

- Blood alcohol level

- Discharge from ED with no recommendations for follow up

- Complete blood count

- Discharge from ED with recommendations to return to ED as needed

- Other blood tests

- Discharge from ED with recommendations to follow up with referring doctor

- Wound care

- Discharge from ED with recommendations to follow up with other doctor/clinic

- Intravenous fluids

- Leaving the ED without being seen by a doctor

- Endotracheal intubation

- Triage out of ED the probability that tests or procedures found associated with mild TBI patients were directly related to the care of mild TBI.

Selected ED records are abstracted for data in several categories chosen by the Centers for Disease Control and Prevention. These categories include patient demographics, physical exam elements, diagnostic tests and procedures, treatments rendered, final ED diagnosis, and disposition. From these categories, we analysed 22 variables that were relevant to the emergency care of isolated mild TBI (box 1). We examined the frequency of occurrence of each of these variables among the isolated mild TBI patients present in the dataset. In addition, each variable was examined for variation across age and insurance categories.

Several NHAMCS variables deserve explanation. The survey divides the USA into four geographical regions of equivalent population size: northeast, mid-west, south and west. Insurance types are coded as private pay, Medicaid, Medicare, Worker's Compensation, self-pay, no charge, and other. To facilitate multivariate analysis, we combined Medicaid with Medicare, and no charge with Worker's Compensation and other.

We defined analgesic medications as paracetamol (acetaminophen), aspirin, opiates, non-steroidal anti-inflammatory drugs, and cyclo-oxygenase (COX)-2 inhibitors. Because muscle relaxants and antiemetics are also used to treat headache, a common mild TBI complaint, these were also included. ${ }^{21}$ Antiemetics included promethazine, prochlorperazine, trimethobenzamide, meclazine, ondansetron, dolasetron, and dimenhydrinate. Muscle relaxants included cyclobenzaprine, carisoprodol, metaxalone, and methocarbamol. Combination drugs containing paracetamol and an opiate (for example, hydorcodone/paracetamol (Vicodin; Abbot Laboratories, Chicago, IL)) were classified as an opiate. Tramadol (Ultram, Ultracet; Ortho-McNeil Pharmaceuticals, Inc., Raritan, NJ) was included in a separate analgesic category called "other".

The number of isolated mild TBI patients who received each of the 22 care items was determined by applying the "patient weight" variable to the sample frequencies. All analyses were done after applying these weights using SUDAAN 7.5 (Research Triangle Park, NC). Annual averages were calculated from the pooled 1998-2000 national estimates and are reported with 95\% confidence intervals. Our sample size is limited by the number of patients in the dataset meeting the definition of isolated mild TBI. We determined the variation within each patient care variable with respect to age and insurance categories using multivariate logistic regression, with control for race, ethnicity, and geographical region. ${ }^{31}$ Thus, each patient care variable became the dependent variable in a logistic regression model where the independent variables were age, insurance type, geographical region, race, and ethnicity. Statistical significance was defined as $\mathrm{p} \leqslant 0.05$.

\section{RESULTS}

Of the $70900 \mathrm{ED}$ visits in the pooled three year sample, 878 (1.23\%) were for mild TBI, and 306 were for isolated mild TBI. After applying the sample weights, these figures corresponded to 4.1 million ED visits for mild TBI and an estimated 459888 for isolated mild TBI. The average number of ED visits annually for isolated mild TBI was an estimated 153 296, representing 56.4/100000 US population. Of patients with isolated mild TBI, 58.4\% were male, and the average (SD) age was 21.0 (1.4) years (range 0-99).

\section{ED care for mild TBI}

\section{Physical examination and diagnostic tests}

The number and proportion of patients with isolated mild TBI who underwent various elements of physical examination 


\begin{tabular}{|c|c|c|c|c|}
\hline ED care variable & $\begin{array}{l}\text { Estimated } \\
\text { no per year }\end{array}$ & $\begin{array}{l}95 \% \text { confidence } \\
\text { interval }\end{array}$ & $\begin{array}{l}\text { \% of mild TBI } \\
\text { cohort }\end{array}$ & $\begin{array}{l}95 \% \text { confidence } \\
\text { interval }\end{array}$ \\
\hline \multicolumn{5}{|l|}{ Physical examination } \\
\hline Pain assessment & 67269 & 39162 to 95375 & 43.8 & 27.4 to 60.4 \\
\hline Mental status exam & 42419 & 26093 to 8745 & 27.7 & 19.3 to 36.0 \\
\hline \multicolumn{5}{|l|}{ Diagnostic tests } \\
\hline CT scan & 63943 & 49770 to 86116 & 44.3 & 35.5 to 53.2 \\
\hline MRI & 534 & 0 to 1580 & 0.35 & 0.0 to 1.0 \\
\hline Other $x$ ray (not chest or extremity) & 36654 & 25607 to 47701 & 23.9 & 17.6 to 30.3 \\
\hline Blood alcohol level & 2941 & 672 to 5209 & 1.9 & 0.4 to 3.4 \\
\hline Complete blood count & 13591 & 6848 to 20334 & 8.9 & 4.6 to 13.1 \\
\hline Other blood test & 15279 & 8293 to 22264 & 9.9 & 5.8 to 14.1 \\
\hline
\end{tabular}

and diagnostic testing are shown in table 1. Of those with a documented pain assessment, an estimated 56161 (83.5\%) were in pain. Although the Glasgow Coma Scale score is part of the clinical definition of mild TBI, NHAMCS does not collect this variable.

\section{Procedures and treatments}

The number and proportion of patients with isolated mild TBI who underwent various procedures and treatments are shown in table 2. Most did not receive an analgesic in the ED (fig 1). Of those with documented pain, only $45.5 \%$ received an analgesic in the ED.

\section{Disposition}

The disposition of patients with isolated mild TBI is shown in table 3. Most were discharged with instructions to follow up with the referring doctor or were referred to another, unspecified doctor or clinic. However, approximately 57082 $(37.2 \%)$ patients with isolated mild TBI per year were instructed either to return to the ED "as needed" or to not require any follow up at all.

\section{Variation in ED care for mild TBI}

Of the 22 patient care variables, we were unable to analyse six because too few patients received them. These variables were MRI scan, blood alcohol level, endotracheal intubation, admitted to intensive care unit, left ED without being seen by a doctor, and triaged out of the ED.

After controlling for race, ethnicity, insurance type and geographical region, increasing age was found to be a significant independent predictor of receiving analgesics for pain in the ED and of receiving other blood tests (that is, a blood test other than a full blood count or blood alcohol level) (table 4). There was no significant insurance related variation in the ED care items examined.

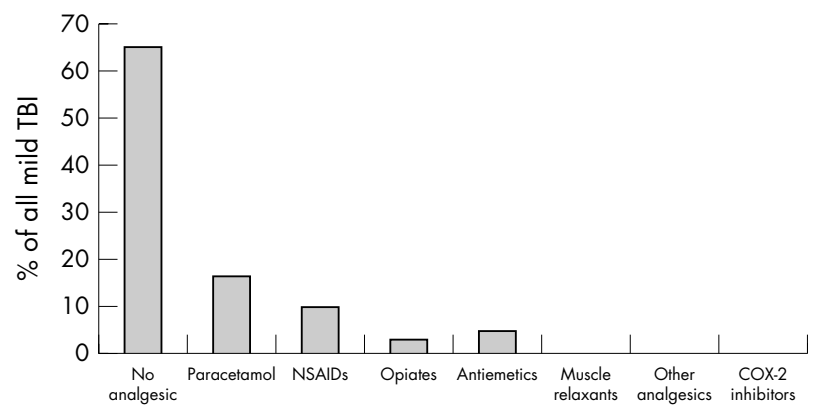

Figure 1 The proportion of all patients with isolated mild TBI who received various analgesics in the emergency department. COX, cyclooxygenase; NSAID, non-steroidal anti-inflammatory drug.

\section{DISCUSSION}

The current study demonstrates that substantial ED resources are devoted to the care of isolated mild TBI in the USA. Over 63000 patients with isolated mild TBI per year undergo computed tomography (ostensibly of the head and brain) and 36600 a non-extremity non-chest $x$ ray, such as of the skull or cervical spine. Each year, between 13000 and 21000 patients with isolated mild TBI had blood tests, and received wound care and intravenous fluids.

We identified several potential deficiencies in ED care for isolated mild TBI. Firstly, less than $44 \%$ of patients had documentation of their pain. As headache is thought to be a major contributing factor to post-concussion syndrome and the primary cause of long term disability after mild TBI, the accurate accounting of pain in all patients with mild TBI is a necessary prerequisite to its treatment. In addition, in the USA, since 2000, all hospitals are required routinely to assess pain in all patients in order to be accredited. ${ }^{32}$ Although the NHAMCS data analysed in the present study precedes the release of these standards, efforts to improve documentation of pain should continue to be a quality improvement priority in EDs that provide care to patients with mild TBI.

Secondly, only $45.5 \%$ of those with documented pain received analgesics. Under-treatment of pain in the ED, especially among children, has been reported by others. ${ }^{33}{ }^{34}$ Post-mild TBI headache is known to be treatable with a variety of agents, from non-steroidal anti-inflammatory drugs to dihydroergotamine. ${ }^{21}$ The effect of early analgesic use on long term outcome after a mild TBI is not known and would be a fruitful area for future investigation.

A final area of deficiency involves the 57000 patients with isolated mild TBI per year who were discharged from EDs without recommendation for any specific follow up. Some were told to come to the ED "as needed", whereas others were told they did not need any follow up at all. Many communities in the USA lack referral centres for evaluation after a mild TBI, which may be partly responsible for these findings. Other researchers have reported similar follow up

Table 2 Emergency department (ED) procedures and treatments for isolated mild traumatic brain injury (TBI)

\begin{tabular}{lrrrr}
\hline ED care variable & $\begin{array}{l}\text { Estimated } \\
\text { no per year }\end{array}$ & $\begin{array}{l}95 \% \text { confidence } \\
\text { interval }\end{array}$ & $\begin{array}{c}\text { \% of mild } \\
\text { TBI cohort }\end{array}$ & $\begin{array}{l}95 \% \text { confidence } \\
\text { interval }\end{array}$ \\
\hline $\begin{array}{l}\text { Procedures } \\
\text { Wound care }\end{array}$ & 26140 & 15662 to 36618 & 17.1 & 11.0 to 23.1 \\
$\quad \begin{array}{l}\text { IV fluids } \\
\text { ET intubation }\end{array}$ & 21566 & $\begin{array}{c}12655 \text { to } 30477 \\
0 \text { to } 2085\end{array}$ & $\begin{array}{l}14.1 \\
8.55\end{array}$ & $\begin{array}{l}8.9 \text { to } 19.2 \\
0.0 \text { to } 1.4\end{array}$ \\
$\begin{array}{l}\text { Treatments } \\
\text { Analgesics }\end{array}$ & 53041 & 38231 to 67851 & 34.6 & 28.3 to 40.9 \\
\hline IV, intravenous; ET, endotracheal. & & & \\
\hline
\end{tabular}




\begin{tabular}{|c|c|c|c|c|}
\hline ED care variable & $\begin{array}{l}\text { Estimated } \\
\text { no per year }\end{array}$ & $\begin{array}{l}95 \% \text { confidence } \\
\text { interval }\end{array}$ & $\begin{array}{l}\text { \% of mild } \\
\text { TBI cohort }\end{array}$ & $\begin{array}{l}95 \% \text { confidence } \\
\text { interval }\end{array}$ \\
\hline \multicolumn{5}{|l|}{ Admitted } \\
\hline Admitted total & 18587 & 10578 to 26596 & 12.1 & 7.5 to 16.7 \\
\hline Admitted to ICU & 1745 & 57 to 3433 & 1.1 & 0.1 to 2.3 \\
\hline Transferred & 2074 & 153 to 3994 & 1.4 & 0.1 to 2.6 \\
\hline \multicolumn{5}{|l|}{ Discharge recommendations } \\
\hline No follow up & 13554 & 6970 to 20138 & 8.8 & 5.0 to 12.7 \\
\hline Return to ED as needed & 43529 & 31699 to 55358 & 28.4 & 22.0 to 34.8 \\
\hline To referring doctor & 28698 & 16180 to 41216 & 18.7 & 11.4 to 26.1 \\
\hline To other doctor/clinic & 63752 & 47986 to 79518 & 41.6 & 33.9 to 49.3 \\
\hline \multicolumn{5}{|l|}{ Other disposition } \\
\hline Left without being seen by doctor & 788 & 0 to 2008 & 0.51 & 0.0 to 1.3 \\
\hline Triaged out of ED & 164 & 0 to 484 & 0.11 & 0.0 to 0.3 \\
\hline
\end{tabular}

patterns. A survey of 68 US level 1 trauma centres revealed that only $34 \%$ referred patients with mild TBI for further evaluation after being discharged from ED. ${ }^{35}$ As postconcussion symptoms affect most patients with mild TBI and can last for more than one year, follow up seems prudent. ${ }^{11-14}$ In fact, in two randomised controlled trials, routine follow up was shown to reduce the severity and number of post-concussion symptoms after mild TBI. ${ }^{19} 20$ In Britain, the Medical Disability Society has recommended routine follow up for all TBI patients. No such recommendations exist in the USA.

In addition to these deficiencies, we identified significant variation in several aspects of ED management across age but not insurance types. Younger patients were less likely to receive analgesics and less likely to undergo blood testing. Children may be less likely to receive analgesics because of their increased tendency to vomit when concussed or because of a belief held by parents and healthcare providers that analgesics are more likely to cause unwanted side effects or mask other symptoms. Uncovering the barriers to the administration of analgesics following a mild TBI in ED would be an important area for future research.

There are several limitations of the current analysis. Our results were derived from the subset of all mild TBI patients with isolated mild TBI. We focused on isolated mild TBI in a deliberate attempt to maximise the chances that tests or procedures found associated with mild TBI patients were directly related to the care of mild TBI. However, it is unclear to what extent patients with isolated mild TBI represent the larger group of mild TBI patients with associated injuries or illnesses. If these two groups differ in the severity of the mild TBI, the ED care for isolated mild TBI might not represent care of non-isolated mild TBI. Unfortunately, the commonly used measure of mild TBI severity, the Glasgow Coma Scale score, is not a part of NHAMCS, thus making this determination impossible.

A second limitation involves NHAMCS data. Because data are abstracted from ED charts after care is delivered, it is not possible to differentiate a care item not performed from one performed but not documented. Furthermore, the NHAMCS data set does not specify the body region imaged by certain diagnostic tests. Thus "CT scan" does not necessarily mean "head CT". Some of these may be non-head computed tomograms. However, because patients in the present cohort did not have any injuries or illnesses other than mild TBI, it may not be unreasonable to assume that computed tomograms were, in fact, of the head. Finally, given that the NHAMCS does not capture information on the Glasgow Coma Scale score, it is possible that patients with a Glasgow Coma Scale score below 13 (and thus with more severe form

Table 4 Variation in emergency department (ED) care for isolated mild traumatic brain injury (TBI): multivariate logistic regression

\begin{tabular}{|c|c|c|c|c|c|}
\hline \multirow[b]{2}{*}{ Dependent variable } & \multicolumn{5}{|c|}{ Independent variables (odds ratio, $95 \%$ confidence interval) } \\
\hline & Age & $\begin{array}{l}\text { Insurance type } \\
\text { (Medicaid/Medicare) }\end{array}$ & $\begin{array}{l}\text { Geographical region } \\
\text { (northeast) }\end{array}$ & Race (white) & $\begin{array}{l}\text { Ethnicity (non- } \\
\text { Hispanic) }\end{array}$ \\
\hline Mental status exam & $1.01(0.99$ to 1.02$)$ & $1.99(0.9$ to 4.2$)$ & $3.84(1.4 \text { to } 10.7)^{*}$ & $1.78(0.6$ to 5.2$)$ & $0.17(0.04 \text { to } 0.7)^{*}$ \\
\hline Pain assessment & 1.01 (0.99 to 1.03$)$ & $0.85(0.3$ to 1.9$)$ & $0.53(0.2$ to 1.5$)$ & $0.54(0.2$ to 1.4$)$ & $0.93(0.3$ to 2.6$)$ \\
\hline CT scan & $1.01(0.9$ to 1.03$)$ & $0.78(0.3$ to 2.2$)$ & $1.76(0.6$ to 5.0$)$ & $2.10(0.8$ to 5.6$)$ & $0.33(0.1$ to .9$)$ \\
\hline Other $x$ ray & $1.005(0.9$ to 1.02$)$ & $0.71(0.2$ to 2.4$)$ & $0.15(0.04 \text { to } 0.5)^{*}$ & $3.68(1.01 \text { to } 13.4)^{*}$ & $0.43(0.1$ to 1.4$)$ \\
\hline Full blood count & $1.03(0.9$ to 1.06$)$ & $4.03(0.7$ to 24.5$)$ & $0.70(0.1$ to 5.5$)$ & $2.25(0.2$ to 22.7$)$ & $0.77(0.1$ to 5.8$)$ \\
\hline Other blood tests & $1.05(1.02 \text { to } 1.08)^{*}$ & $1.93(0.9$ to 8.8$)$ & $1.63(0.2$ to 12.0$)$ & $2.13(0.4$ to 11.7$)$ & $1.25(0.2$ to 7.6$)$ \\
\hline Wound care & $1.005(0.9$ to 1.03$)$ & $0.70(0.1$ to 3.5$)$ & $0.64(0.2$ to 2.7$)$ & $0.69(0.2$ to 2.5$)$ & $1.16(0.3$ to 4.4$)$ \\
\hline Intravenous fluids & $1.01(0.9$ to 1.03$)$ & $0.78(0.1$ to 5.4$)$ & $0.76(0.14$ to 4.1$)$ & $2.33(0.3$ to 19.8$)$ & $0.24(0.05$ to 1.1$)$ \\
\hline Analgesics & $1.01(0.9$ to 1.03$)$ & $0.84(0.3$ to 2.8$)$ & $0.54(0.2$ to 1.9$)$ & $0.48(0.2$ to 1.1$)$ & $0.58(0.2$ to 1.9$)$ \\
\hline Analgesics for pain & $1.03(1.0 \text { to } 1.1)^{*}$ & $1.39(0.3$ to 7.6$)$ & $3.08(0.4$ to 24.4$)$ & $0.36(0.1$ to 1.4$)$ & $1.005(0.2$ to 5.0$)$ \\
\hline Admitted to hospital & $1.004(0.9$ to 1.02$)$ & $2.71(0.6$ to 12.0$)$ & $1.05(02$ to 4.5$)$ & $0.97(0.2$ to 3.7$)$ & $0.97(0.2$ to 5.0$)$ \\
\hline Transferred to other facility & $1.01(0.9$ to 1.1$)$ & $0.27(0.01$ to 12.5$)$ & $1.09(0.03$ to 42.6$)$ & $0.05(0.003 \text { to } 0.7)^{*}$ & Too few patients \\
\hline Discharged without follow up & $1.01(0.9$ to 1.09$)$ & $0.60(0.1$ to 2.9$)$ & $0.61(0.1$ to 4.0$)$ & $1.60(0.2$ to 10.4$)$ & Too few patients \\
\hline $\begin{array}{l}\text { Discharged with recommendation } \\
\text { to return to } E D \text { as needed }\end{array}$ & 0.99 (0.9 to 1.01$)$ & 1.42 (0.5 to 3.8$)$ & 1.36 (0.4 to 4.0$)$ & $1.92(0.5$ to 6.9$)$ & $1.05(0.4$ to 2.9$)$ \\
\hline $\begin{array}{l}\text { Discharged with recommendation } \\
\text { to follow up with referring doctor }\end{array}$ & 1.001 (0.9 to 1.03$)$ & $0.51(0.14$ to 1.8$)$ & $0.70(0.2$ to 2.5$)$ & $1.27(0.4$ to 3.8$)$ & $0.56(0.1$ to 2.1$)$ \\
\hline $\begin{array}{l}\text { Discharged with recommendation } \\
\text { to follow up with other doctor or clinic }\end{array}$ & $0.99(0.9$ to 1.02$)$ & $0.53(0.2$ to 1.4$)$ & $0.69(0.2$ to 2.4$)$ & $0.63(0.2$ to 1.7$)$ & $1.11(0.4$ to 3.2$)$ \\
\hline
\end{tabular}


of TBI) have been included in this cohort. Although it is unlikely that this would differentially affect a particular subgroup to produce bias, future efforts to include Glasgow Coma Scale score as a variable captured in the NHAMCS dataset should be encouraged.

Validation of these findings through the prospective collection of ED care data could address the problems inherent in the NHAMCS data collection system. If the deficiencies and variations in ED care observed here are confirmed, the creation of clinical practice guidelines could help to standardise and improve care, according to the Institute of Medicine's Committee on Clinical Practice Guidelines. ${ }^{26}$ In Europe, guidelines for mild TBI have been developed by the European Federation of Neurological Societies, the World Federation of Neurosurgical Societies, and the Scandinavian Neurosurgical Society. ${ }^{27-29}$ These guidelines address indications for neuroimaging, hospital admission, and follow up. Our data can continue to advance the process of development of guidelines for mild TBI by revealing additional areas of significant variation in ED care. Based on our results, guidelines for the emergency management of mild TBI should also include pain documentation, pain management (especially among children), documentation of the Glasgow Coma Scale score, and referral for follow up after discharge from ED.

The development of guidelines for the management of mild TBI has the potential not only to reduce variation in ED care and thus disability after mild TBI but also to raise overall awareness of an injury that not infrequently goes undiagnosed in the ED setting. ${ }^{36}$ By improving aspects of ED care such as pain management and follow up recommendations, ED guidelines for mild TBI have the potential to reduce the tremendous burden of an injury that currently has no treatment.

In summary, substantial ED resources are devoted to the care of mild TBI. However, the present study found several areas of deficient care. Many patients are discharged without recommendations for specific follow up. Pain is underreported and under-treated. In addition, we observed variation in several important aspects of ED care. These findings suggest that emergency management for mild TBI could be improved through the development of guidelines specific for mild TBI.

\section{ACKNOWLEDGEMENTS}

The authors wish to thank S Fisher, $\mathrm{PhD}$, for her help with the statistical analysis and P Auinger for her assistance with SUDAAN programming.

\footnotetext{
Authors' affiliations

J J Bazarian, J McClung, S M Schneider, Department of Emergency Medicine, University of Rochester Medical Center, Rochester, NY, USA Y T Cheng, Hospital Max Peralta, San Josè, Costa Rica

W Flesher, Department of Community and Preventive Medicine, University of Rochester Medical Center, Rochester, NY, USA

Dr Bazarian is supported by a National Institutes of Neurologic Disorders and Stroke Grant 1 K23 NS 41952-04.

Competing interests: none declared

This work was presented at the Fiffh World Congress on Traumatic Brain Injury, 24 May 2003, Stockholm, Sweden.

\section{REFERENCES}

1 Jager TE, Weiss HB, Coben JH, et al. Traumatic brain injuries evaluated in US emergency departments, 1992-1994. Acad Emerg Med 2000;7:134-40.

2 Centers for Disease Control and Prevention. National Center for Injury Prevention and Control. Report to Congress. Mild Traumatic Brain Injury in the United States: Steps to Prevent a Serious Public Health Problem. Atlanta, GA: Centers for Disease Control and Prevention, 2003.
}

3 Cassidy JD, Carroll $\amalg$, Peloso PM, et al. Incidence, risk factors and prevention of mild traumatic brain injury: Results of the WHO Collaborating Centre Task Force on Mild Traumatic Brain Injury. J Rehabil Med 2004;43:28-60.

4 von Holst H, Cassidy JD. Mandate of the WHO Collaborating Centre Task Force on Mild Traumatic Brain Injury. J Rehabil Med 2004;(43 suppl):8-10.

5 National Institutes of Health. NIH Consensus Development Panel on Rehabilitation of Persons with Traumatic Brain Injury. JAMA 1999;282:974-83.

6 Jagoda AS, Cantrill SV, Wears RL, et al. Clinical policy: neuroimaging and decision-making in adult mild traumatic brain injury in the acute setting. Ann Emerg Med 2002;40:231-49.

7 Jorge RE, Robinson RG, Starkstein SE, et al. Influence of major depression on 1 -year outcome in patients with traumatic brain injury. J Neurosurg 1994:81:726-33.

8 Bohnen N, Twijnstra A, Jolles J. Post-traumatic and emotional symptoms in different subgroups of patients with mild head injury. Brain Inj 1992;6:481-7.

9 Dikmen SS, Temkin NR, Machamer JR, et al. Employment following traumatic head injuries. Arch Neurol 1994;51:177-86.

10 Bazarian JJ, Atabaki S. Predicting postconcussion syndrome after minor traumatic brain injury. Acad Emerg Med 2001;8:788-95

11 Jay GW, Goka RS, Arakaki AH. Minor traumatic brain injury: review of clinical data and appropriate evaluation and treatment. J Insurance Med (Seattle) 1996;27:262-82.

12 Borczuk P. Mild head trauma. Emerg Med Clin North Am 1997;15:563-79.

13 Bazarian JJ, Wong T, Harris M, et al. Epidemiology and predictors of postconcussive syndrome after minor head injury in an emergency population. Brain Inj 1999; 13:173-89.

14 Levin HS, Mattis S, Ruff RM, et al. Neurobehavioral outcome following minor head injury three center study. J Neurosurg 1987:66:234-43.

15 Carroll L, Cassidy JD, Peloso PM, et al. Prognosis for mild traumatic brain injury: results of the WHO Collaborating Centre Task Force on Mild Traumatic Brain Injury. J Rehabil Med 2004;(43 suppl):84-105.

16 Borg J, Holm L, Cassidy JD, et al. Diagnostic procedures in mild traumatic brain injury: results of the WHO Collaborating Centre Task Force on Mild Traumatic Brain Injury. J Rehabil Med 2004;(43 Suppl):61-75.

17 Bazarian J, Hartman M, Delahunta E. Minor head injury: predicting follow-up after discharge from the Emergency Department. Brain Inj 2000;14:285-94.

18 Seelig JM, Becker DP, Miller JD, et al. Traumatic acute subdural hematoma: major mortality reduction in comatose patients treated within four hours. N Engl J Med 1981;304:1511-18.

19 Ponsford J, Willmott C, Rothwell A, et al. Impact of early intervention on outcome after mild traumatic brain injury in children. Pediatrics 2001;108:1297-303.

20 Wade DT, King NS, Wenden FJ, et al. Routine follow up after head injury: a second randomised controlled trial. I Neurol Neurosurg Psychiatry 1998;65:177-83

21 Mittenberg W, Canyock EM, Condit D, et al. Treatment of post-concussion syndrome following mild head injury. J Clin Exp Neuropsychol 2001;23:829-36.

22 Klassen TP, Reed MH, Stiell IG, et al. Variation in utilization of computed tomography scanning for the investigation of minor head trauma in children: a Canadian experience. Acad Emerg Med 2000;7:739-44.

23 Stiell IG, Wells GA, Vandemheen K, et al. Variation in ED use of computed tomography for patients with minor head injury. Ann Emerg Med 1997;30:14-22.

24 von Wild K, Terwey S. Diagnostic confusion in mild traumatic brain injury (MTBI). Lessons from clinical practice and EFNS - inquiry. European Federation of Neurological Societies. Brain Inj 2001;15:273-7.

25 Ingebrigtsen T, Romner B. Management of minor head injuries in hospitals in Norway. Acta Neurol Scand 1997;95:51-5.

26 Field MJ, Lohr KN. Guidelines for clinical practice: from development to use. Natl Acad Sci 1992:1-22.

27 Vos PE, Battistin L, Birbamer G, et al. EFNS guideline on mild traumatic brain injury: report of an EFNS task force. Eur J Neurol 2002;9:207-19.

28 Fabbri A, Servadei F, Marchesini G, et al. Prospective validation of a proposal for diagnosis and management of patients attending the emergency department for mild head injury. J Neurol, Neurosurg Psychiatry 2004;75:410-16

29 Ingebrigtsen T, Romner B, Kock-Jensen C. Scandinavian guidelines for initial management of minimal, mild, and moderate head injuries. J Trauma 2000;48:760-6.

30 Centers for Disease Control and Prevention. National Hospital Ambulatory Medical Care Survey. Available at www.cdc.gov/nchs/about/major/ahcd/ ahcdl.htm (accessed 8 October 2002).

31 Smedley BD, Stith AY, Nelson AR, eds. Unequal Treatment: Confronting Racial and Ethnic Disparities in Health Care. Washington DC: Institute of Medicine, 2003.

32 Phillips DM. JCAHO pain management standards are unveiled. Joint Commission on Accreditation of Healthcare Organizations [comment]. JAMA 2000;284:428-9.

33 Guru V, Dubinsky I. The patient vs. caregiver perception of acute pain in the emergency department. J Emerg Med 2000;18:7-12.

34 Petrack EM, Christopher NC, Kriwinsky J. Pain management in the emergency department: patterns of analgesic utilization. Pediatrics 1997:99:711-14.

35 Blostein $\mathbf{P}$, Jones SJ. Identification and evaluation of patients with mild traumatic brain injury: results of a national survey of level I trauma centers. $J$ Trauma 2003;55:450-3.

36 Chambers J, Cohen SS, Hemminger L, et al. Mild traumatic brain injuries in low-risk trauma patients. J Trauma 1996;41:976-80. 